\title{
New proposal for production of bioactive compounds by supercritical technology integrated to a sugarcane biorefinery
}

\author{
Diego T. Santos $\cdot$ Juliana Q. Albarelli • \\ Maurício A. Rostagno • Adriano V. Ensinas • \\ François Maréchal • M. Angela A. Meireles
}

Received: 18 December 2013/Accepted: 8 April 2014/Published online: 23 April 2014

(C) Springer-Verlag Berlin Heidelberg 2014

\begin{abstract}
The construction of a supercritical fluid extraction (SFE) plant inside or in close proximity to a sugarcane biorefinery producing first and second generation ethanol demonstrated to be very promising, increasing the economic potential of the SFE process in up to $57 \%$, since the SFE plant could use directly the ethanol, $\mathrm{CO}_{2}$, heat, and electricity already available, with lower prices. In this study, Brazilian ginseng roots were used as model bioactive compounds source and first the statistical influence of the extraction conditions including pressure (10-20 MPa), temperature $(323-363 \mathrm{~K})$, and $\mathrm{CO}_{2} /$ ethanol proportion ratio $(90: 10,50: 50$, and $0: 100 \%, w / w)$ on the $\beta$-ecdysone content in the extracts was experimentally evaluated and compared with literature results. SFE process evaluated experimentally at the present study showed higher selective extraction for $\beta$-ecdysone from Brazilian ginseng roots, providing an extract with up to 2.16 times higher $\beta$-ecdysone than the results obtained in previous studies. Thermal integration of the SFE process diminished energy requirements of the process, resulting in a reduction of cold utility requirement of $87 \%$ and a final electricity demand of $7.5 \mathrm{kWh} / \mathrm{g}$ of $\beta$-ecdysone in the extract. In a situation in which the Brazilian ginseng roots price was increased to $4.71 \mathrm{USD} / \mathrm{g}$, only the SFE integrated with the biorefinery solution would be economically feasible.
\end{abstract}

D. T. Santos · M. A. Rostagno - M. A. A. Meireles LASEFI/DEA/FEA (School of Food Engineering), UNICAMP (University of Campinas), Cidade Universitária "Zeferino Vaz", Rua Monteiro Lobato, 80, Campinas, SP 13083-862, Brazil

D. T. Santos ( () J. Q. Albarelli · A. V. Ensinas · F. Maréchal Industrial Process and Energy Systems Engineering (IPESE), École Polytechnique Fédérale de Lausanne (EPFL), Station 9, 1015 Lausanne, Switzerland

e-mail: diego_tresinari@yahoo.com.br
Finally, the selling of the ginseng roots leftover could be an interesting answer to increase the economical attractiveness of the integrated SFE process to the biorefinery.

Keywords Biorefinering - Biomass valorization · Clean technologies · Process integration · Supercritical technology $\cdot$ Bioactive compounds

\section{Introduction}

Supercritical fluid extraction (SFE) has proven to be technically and economically feasible, presenting several advantages, including environment benefits, when compared to traditional solid-liquid extraction methods (Straccia et al. 2012). However, after three decades of development, of the over 200 commercial plants in the world, none is located in Latin America (Prado et al. 2011). The high cost of investment when compared to classical low-pressure equipments, of steam distillation and organic solvent extraction, is pointed as the main drawback for the installation of a SFE industrial unit. However, the cost of manufacturing (COM) products by SFE, when all costs involved in the process are taken into account, can be extremely competitive with the COM of extracts obtained by traditional extraction techniques depending on the bioactive compounds source (Meireles 2008).

COM estimation is important to evaluate the feasibility of an industrial project. The most used COM estimations for industrial processes are based on Turton methodology. The economic evaluation consists in determining the parameters influences in the COM: capital investment (FCI), cost of operational labor (COL), cost of raw material (CRM), cost of utilities (CUT), and cost of waste treatment (CWT) (Turton et al. 2003). Generally, for a SFE process 
the raw material cost is related to the plant material and the solvent lost during the process. If a by-product is used as the bioactive compounds source, for instance, its value can be considered zero. $\mathrm{CO}_{2}$ loss is mainly due to depressurization of the extractor at the end of each batch and cosolvent loss, if employed, is lost in the residue stream and in the condenser. Pre-processing costs involve drying and comminution of raw material. Utility costs comprise producing heat exchange agents and the electricity used in the processes. The CWT may be neglected in SFE because the residue of the process is a dry solid vegetable matrix that may be incorporated into the soil or commercialized as a by-product, as it does not contain any residue of toxic solvents. The $\mathrm{CO}_{2}$ and co-solvent lost needs no treatment because presents no harm to the environment or human health in small quantities (Pereira and Meireles 2010).

Nowadays, the image of a sustainable society is focused on a society that has a decentralized local-scale production based on local characteristics of the environment so that chemicals and energy flows can be supplied from diverse biomass and other renewable resources. In this sense, supercritical technology is being considered to be one key in the realization of decentralized processes (Arai et al. 2009). The possibility of constructing a SFE plant in close proximity to an alcoholic fermentation facility that produces high purity $\mathrm{CO}_{2}$ as a by-product and ethanol, preferred co-solvent for coupling with $\mathrm{CO}_{2}$ was mentioned by some researchers (King and Srinivas 2009), on the other hand, none evaluation was done until the present date.

Recently, scientists and executives have shown great interest on Brazilian ginseng (Pfaffia glomerata) roots, due to besides similarity in appearance $P$. glomerata extracts have also demonstrating similar effects to Panax ginseng (Santos et al. 2012a). Since the pharmaceutical properties of these $P$. glomerata roots extracts have been attributed to $\beta$-ecdysone content (Zimmer et al. 2006), selective extraction process should be applied. In this context, SFE process has been successfully applied for different bioactive compounds sources, including $P$. glomerata roots. Leal et al. (2010) obtained an extract employing $\mathrm{CO}_{2}+$ ethanol (90:10\%, w/w) at $20 \mathrm{MPa}$ and $303 \mathrm{~K}$ as extracting solvent with a concentration of up to $3.7 \%$ for $\beta$-ecdysone (which is 3.8-fold higher to the concentration in the commercial extracts), which indicates the possible use of those extracts directly in the commercial pharmaceutical products.

This work is a part of a project that aims at providing a way to valorize the Brazilian ginseng plant. In an effort to increase revenues from the feedstock, we assumed that co-products would be extracted by SFE under optimized conditions (determined in this study) prior to the thermochemical conversion. In this study, we evaluated the integration of the SFE process into a sugarcane biorefinery producing first and second generation ethanol to provide comprehensive perspectives on the possibility of constructing the first industrial SFE unit in Brazil. Critical parameters of the proposed integrated biorefinery, such as CRM and CUT, were changed for evaluating the thermal and economic benefits gained with this new arrangement.

\section{Materials and methods}

\section{Experimental methodology}

A home-made unit, described by Pasquel et al. (2000), was used for the experiments that use $\mathrm{CO}_{2}$ and ethanol mixtures, while another home-made recently constructed unit described by Santos et al. (2012a) was used in the experiments that only ethanol is used. The setup of these units is the same (Fig. 1), both having extracting solvent or solvents pressurization, bioactive compounds extraction, and extract recovery steps, only differing their extractor size and the way to provide the heating for the extractor. The latter uses an electrical heating jacket and its extractor volume is $6.57 \mathrm{~cm}^{3}$, while the former uses a thermostatically controlled bath for heating the extractor with a volume of $415 \mathrm{~cm}^{3}$. Different amounts of dried $(8.9 \%$ moisture) and milled (particles with a diameter of $7.9 \mu \mathrm{m})$ raw material $(P$. glomerata roots) were placed in each extraction unit, then, the amount of total solvent was adjusted to keep the solvent mass to feed mass ratio constant $(S / F=50)$ in all experiments. The criterion adopted in the present study has proved to be efficient for comparison of results obtained in different equipments with different extraction vessel volumes (Prado et al. 2011). Teflon column and glass beads (mean diameter of $0.005 \mathrm{~m}$ ) were used to fill part of the $415 \mathrm{~cm}^{3}$ extraction vessel volume to reduce the empty space to place the raw material to be extracted in order to reduce the consumption of ethanol in each run. The static and dynamic extraction periods always were $5 \mathrm{~min}$ and $1 \mathrm{~h}$, respectively. The assays were done in duplicate.

The $\beta$-ecdysone content determination in the extracts were carried out on a high-performance liquid chromatography (HPLC) system (Waters Corp., Milford, MA, USA) following method developed by Rostagno et al. (2014).

The experimental design used was a full factorial design $(2 \times 2 \times 3)$ that was totally randomized without replication. The independent variables studied were temperature (323 and $363 \mathrm{~K}$ ), pressure (10 and $20 \mathrm{MPa}$ ), and $\mathrm{CO}_{2}$ /ethanol proportion ratio $(\%, \mathrm{w} / \mathrm{w})(90: 10,50: 50$, and $0: 100)$. The response variable was $\beta$-ecdysone content in the extract (\%).

Statistical analyses were performed using analyses of variance (ANOVA). The mean values were considered significant at $p<0.05$ and very significant at $p<0.01$. Statistica software (release 7, StatSoft, TUL, USA) 


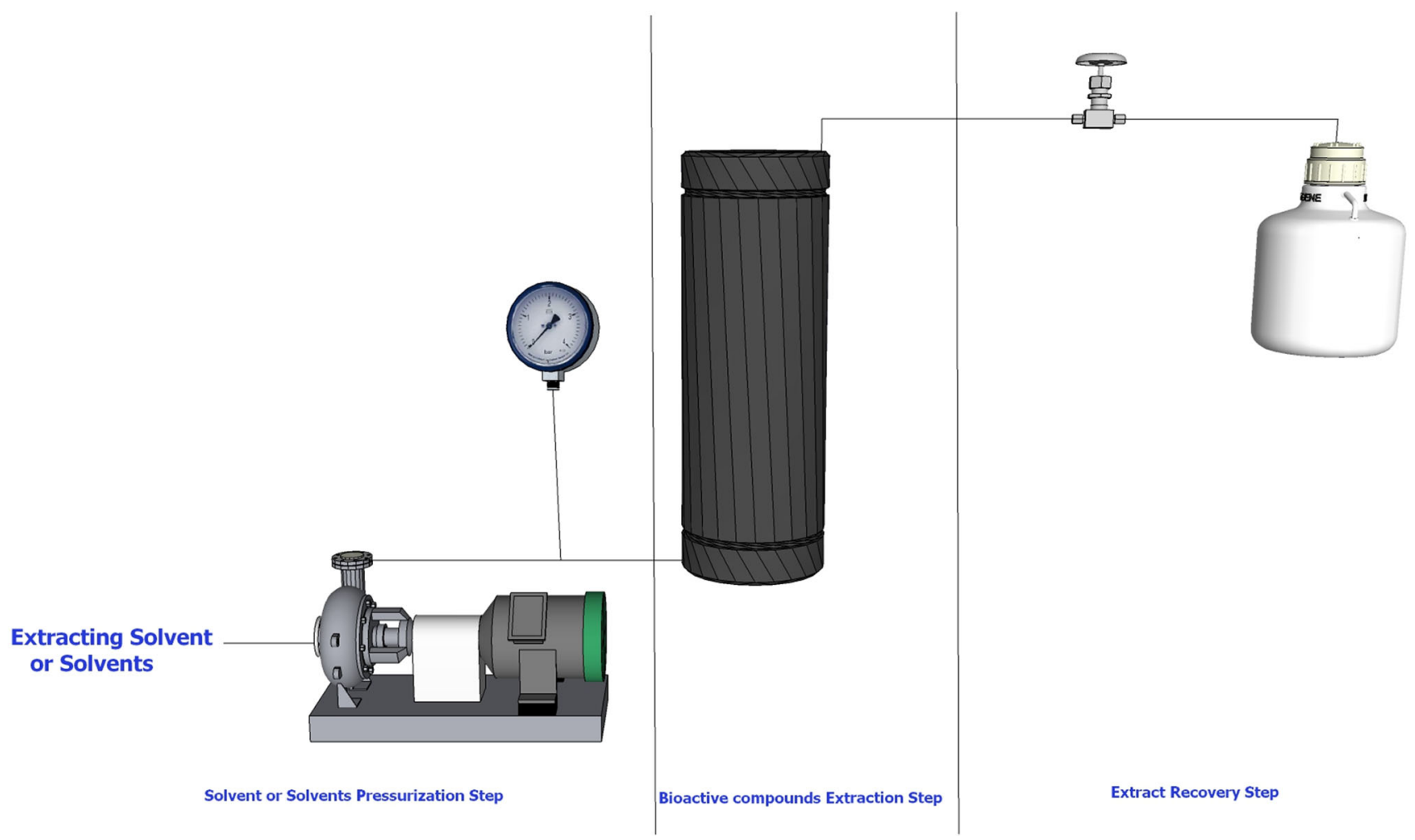

Fig. 1 Schematic diagram of the laboratory-scale home-made units setup used for the pressurized fluid extractions

(STATISTICA 2001) was used to calculate the effects of the temperature, pressure, and $\mathrm{CO}_{2}$ /ethanol proportion ratio on the $\beta$-ecdysone content in the extracts.

Process simulation methodology

A flowsheeting model of the SFE process was developed in the ASPEN PLUS ${ }^{\circledR}$ v. 7.2 software in order to compute the mass and energy balances. A thermal model of the production process was solved in MATLAB-based platform OSMOSE using state variables obtained in the detailed simulation of all the equipment and conversion steps of the process. The OSMOSE platform is a tool for the design and the analysis of integrated energy systems, developed at École Polytechnique Fédérale de Lausanne in Switzerland. Its goal is to enable the integration of flowsheeting tools, process integration, and costing tools to realize the study of integrated energy conversion systems (Bollinger 2010).

It was analyzed the extraction of Brazilian ginseng roots under two different operational conditions:

Scenario the simulation of the process considering the I operation of the system under the conditions experimentally studied by Leal et al. (2010)

Scenario the simulation of the process considering the II operation of the system under the optimized condition determined experimentally in the present study
The two conditions were evaluated energetically considering two possible scenarios (Fig. 2):

Scenario a stand-alone SFE plant, being the heat and A electricity supplied by the burning of the residue of the SFE extraction (roots) and complementary fuel, if necessary, in a cogeneration system shared with a sugarcane biorefinery. In this scenario, it is considered the thermal integration of the stand-alone SFE plant thermal streams

Scenario a SFE plant located inside a sugarcane B biorefinery producing first and second generation ethanol, so the thermal integration would be performed considering heat exchange between the two processes. The thermal requirements would be fulfilled by a cogeneration unit burning the regular fuels from the biorefinery [Part of bagasse, leaves, hydrolysis waste, biogas from xylose and vinasse, ginseng roots leftover after extraction of the SFE extraction (roots)]. In this scenario, it is considered the thermal integration of the standalone SFE plant thermal streams and the sugarcane biorefinery heat streams

For the conditions evaluated in Scenario B, it was always considered the same process and characteristics for 


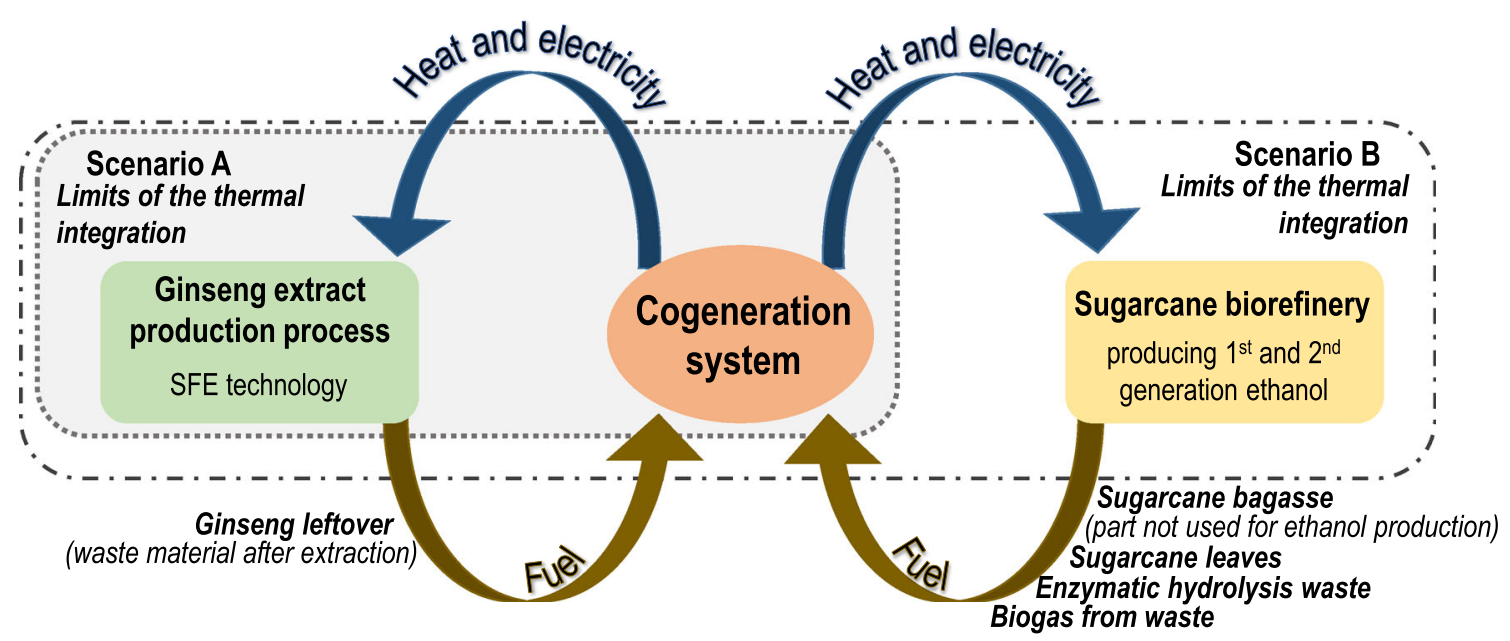

Fig. 2 Scheme of Scenarios A and B: $A$ —stand-alone SFE plant with shared cogeneration with a sugarcane biorefinery; $B$ —SFE plant integrated with a sugarcane biorefinery

the sugarcane biorefinery, producing both first and second generation ethanol.

\section{Simulation of the SFE plant}

The flowsheet of the analyzed process is shown in Fig. 3. Table 1 shows the characteristics of each flow calculated by simulation for Scenarios I and II. The simulation of the SFE plant was performed using the commercial simulator ASPEN PLUS $^{\circledR}$ v. 7.2. For the Brazilian ginseng roots extraction, it was considered a prior preparation of the material in which the roots were cleaned, air dried using heated air at $373 \mathrm{~K}$ and milled. The preparation system was simulated as a separation block, to represent the cleaning system (block CLEANING, Fig. 3), and a flash to simulate the drying in which the mass flow of air was adjusted to enable $10 \%$ of biomass final moisture (block DRYER, Fig. 3). The milling system was considered only at the OSMOSE programming level, so the electricity demand for this process was taken into account.

The prepared roots were introduced in an extraction vessels were $\mathrm{CO}_{2}$ and ethanol were pumped at the desired proportions $\left[\mathrm{CO}_{2} /\right.$ ethanol proportion ratio of $90: 10 \%(\mathrm{w} /$ w)], pressure $(10$ or $20 \mathrm{MPa}$ ), and temperature (303 or $323 \mathrm{~K})$. The extractor was simulated as an extraction block (block EXTRACTOR, Fig. 3) in which it was imposed the extraction yields and $\beta$-ecdysone content according with the data from the experimental results. Although the extraction process is a non-continuous process, it can be modeled as a steady-state process since it was considered different extraction vessels operating in parallel, which enables a continuous production of extract.

After extraction, $\mathrm{CO}_{2}$ was recovered through 2 flash tanks operating at 6.5 and $0.1 \mathrm{MPa}$, respectively. Lower pressure $\mathrm{CO}_{2}$ was compressed to $6.5 \mathrm{MPar}$ and liquefied to be reused in the system with a loss of $2 \%$. The flash tanks were simulated as a flash equipment (blocks F-C1 and F-C2, Fig. 3), the compression and liquefaction were simulated as compressor equipment (block COMP-C1, Fig. 3) followed by a heat exchanger (block H-C2, Fig. 3). Ethanol was separated from the extracted compounds by evaporation and recycled to the process. The evaporator was simulated as a set of a heat exchanger and a flash tank (blocks H-E2 and F-E1, Fig. 3). It was considered a loss of $5 \%$ of ethanol and the cooling of ethanol in a heat exchanger to the ethanol inlet temperature $(298 \mathrm{~K})$ prior to its reuse.

The operational conditions admitted, as well as the extraction yield and $\beta$-ecdysone content in the extract, are shown in Table 2. It was considered the operation of the system under the conditions experimentally studied by Leal et al. (2010) and under the conditions obtained experimentally and discussed at the present paper.

Simulation of the sugarcane biorefinery producing first and second generation ethanol

The sugarcane biorefinery model producing first and second generation ethanol analyzed sharing only the cogeneration system with the extraction process (Scenario A) or integrated with the extraction process (Scenario B) is described in Ensinas et al. (2013) and Albarelli et al. (2013).

The simulation of the first generation ethanol production considered the steps of: juice extraction and treatment, concentration and sterilization, fermentation, distillation, and dehydration. It was simulated the technologies available in modern ethanol distilleries in Brazil, including 


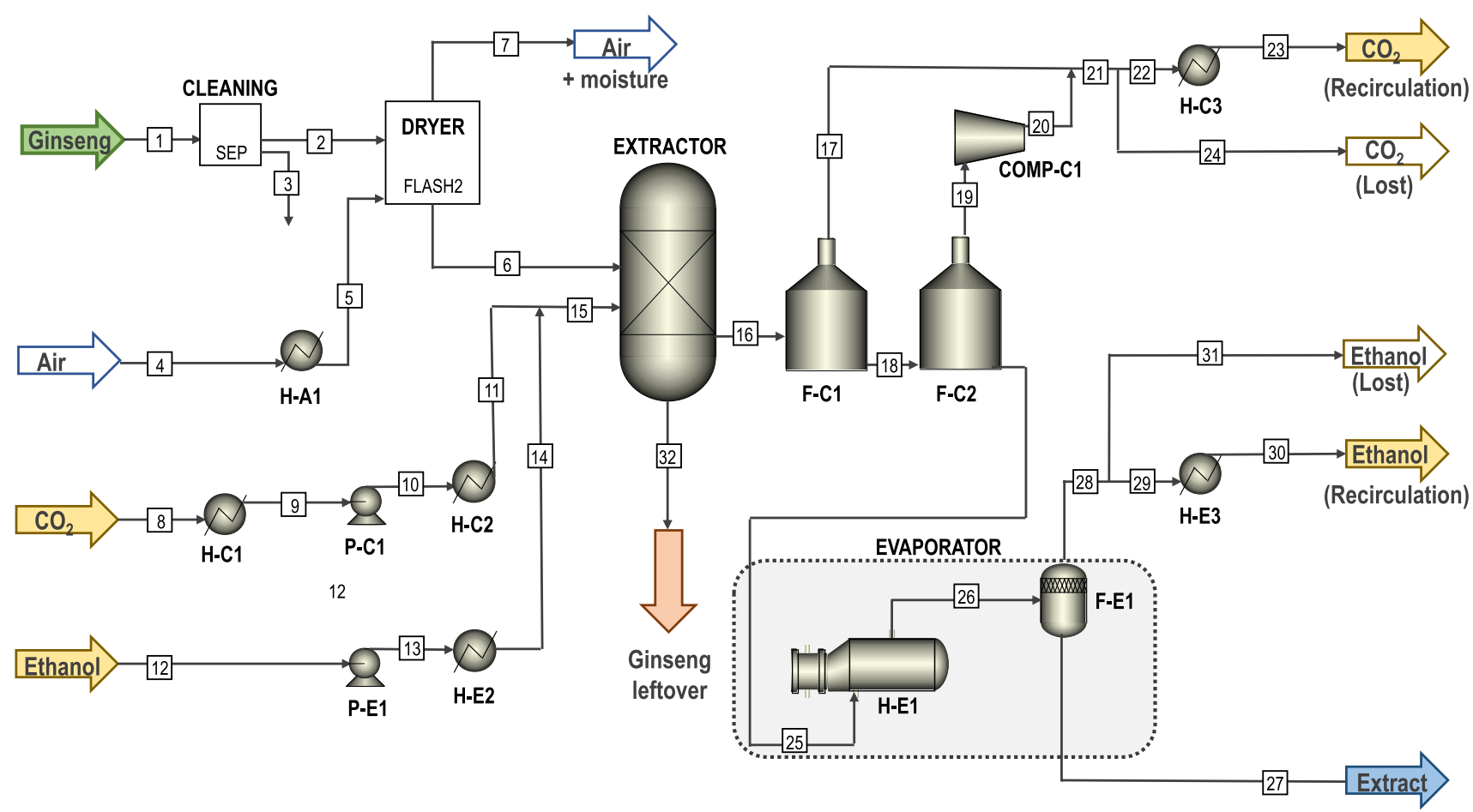

Fig. 3 Flowsheet of the supercritical fluid extraction (SFE) process developed in the ASPEN PLUS ${ }^{\circledR}$ software

sugarcane dry cleaning, concentration in multi-effect evaporators, sterilization of the juice before entering the fermentation system, and ethanol dehydration using monoethylene glycol. For the second generation ethanol production, it was considered the use of sugarcane bagasse to ethanol production. It was considered the steps of drying and milling of the material, catalyzed steam explosion pretreatment flowed by enzymatic hydrolysis. The hydrolyzate was concentrated and mixed with the concentrated extracted juice of the first generation process and sent to the fermentation unit. The xylose steam obtained from pretreatment and vinasse obtained from the distillation were used for biogas production in a biodigestor. Table 3 shows the main parameters considered for the simulation of the sugarcane biorefinery.

Simulation of the cogeneration system

The cogeneration system was developed considering a steam cycle operating in a pressure of $9 \mathrm{MPa}$ with extracting and condensing turbines (Ensinas et al. 2013). It was simulated the burning of the residues considered in the analysis in the software ASPEN PLUS ${ }^{\circledR}$ v. 7.2. The burner was simulated as a stoichiometric reactor where air in excess $(35 \%)$ was used to the reaction (Albarelli et al. 2013). The off gases were cooled to $473 \mathrm{~K}$ and the heat was used as the heat source to the steam network available at OSMOSE platform.

Thermal process integration

All the process design case studies were thermal integrated using the pinch method (Linnhoff et al. 1982), aiming at the reduction of process steam requirements. Based on the pinch analysis methodology, the optimal thermal process integration is computed after defining the maximum heat recovery potential between hot and cold streams and considering a minimum approach temperature $\Delta T_{\text {min }}$. In this extend, it was considered as $\Delta T_{\min } / 2$ for the streams 2,5 , and $20{ }^{\circ} \mathrm{C}$ for liquid streams, streams with phase change, and gases in high temperature (boiler outlet), respectively. The energy-integration model is send to the slave optimization, which runs a combined mass and energy integration in order to reduce the operating cost of the system, using the Mixed Integer Linear Programming solver GLPSOL (GLPK 2014). In the optimization, the amount of cold and hot utility is varied in order to minimize the objective function that is the operating costs (Marechal and Kalitventze 1998). In order to run the thermal optimization hot and cold utilities were defined. The hot utility was defined as steam generated at the cogeneration system, using as fuel ginseng roots leftover after extraction. For the cold 


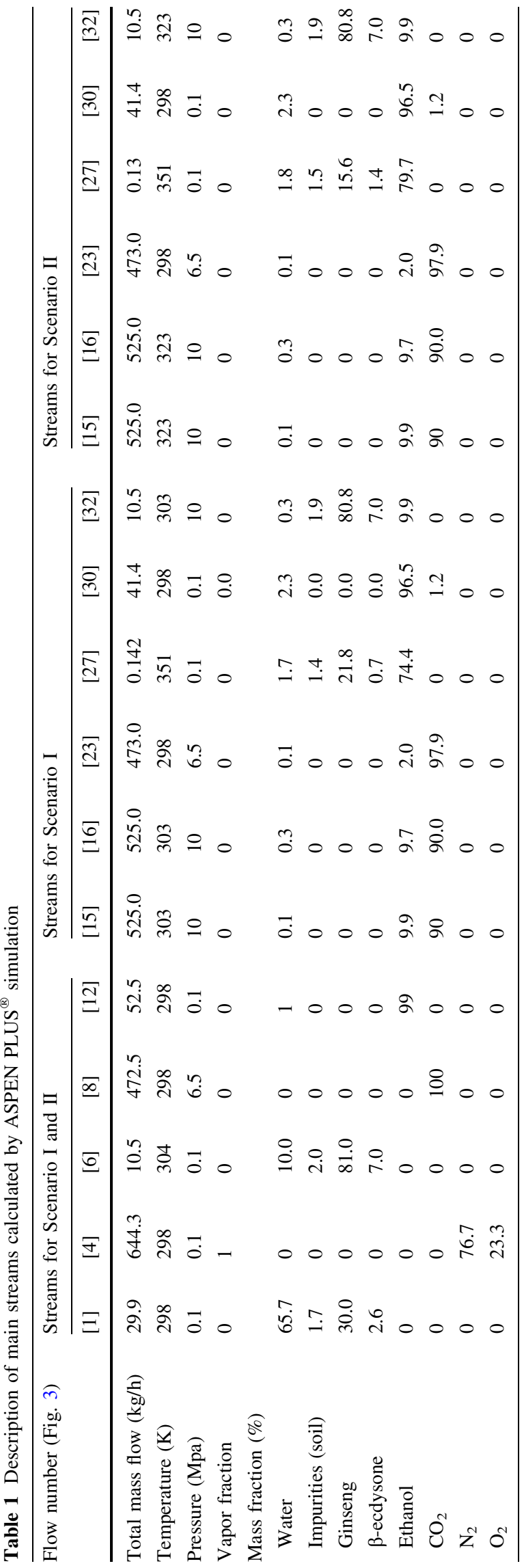

utilities, it was considered water $298 \mathrm{~K}$ and liquid nitrogen at $250 \mathrm{~K}$. Data of the streams available for thermal integration are presented in Table 4.

Economic cost-benefit analysis

The economic analysis for each scenario were evaluated regarding the CRM, CUT and benefit for selling the products (extract and ginseng roots leftover after extraction), being the economic potential (EP) value calculated by the total revenue of sold products deducted from the cost expended. EP is a measure of economic performance at the preliminary design stage of future integrated biorefineries (Tang et al. 2013). Table 5 shows the input data used for the EP estimation and sensitivity analysis. The prices for ethanol and $\mathrm{CO}_{2}$ as well as for the electricity are different according with the scenario evaluated. For Scenario B, lower prices are attained, regarding the mention input of the extraction process, as they are bought by the production price at the biorefinery. At Scenario B, it was also considered a price for selling the ginseng roots leftover after extraction that was not evaluated in Scenario A. The possibility of selling the ginseng roots leftover was evaluated in this scenario as after the integration with the biorefinery no heat is required and electricity is bought at a lower price, therefore, the selling of this material could possibly bring a higher economic benefit than burning to produce energy. A sensitivity analysis was accomplished in order to evaluate the influence of the ginseng roots price and the ginseng roots leftover after extraction as a wide range of values were found in the literature for then.

\section{Results and discussion}

Effects of experimental condition on bioactive compounds content in the extract

Leal et al. (2010) obtained an extract employing $\mathrm{CO}_{2}+$ ethanol (90:10\%,w/w) at $20 \mathrm{MPa}$ and $303 \mathrm{~K}$ as extracting solvent with a concentration of up to $3.7 \%$ for $\beta$-ecdysone (which is 3.8-fold higher to the concentration in the commercial extracts), which indicates the possible use of those extracts directly in the commercial pharmaceutical products. Based on these findings, this work first aims the optimization of $\beta$-ecdysone recovery by SFE. The effects of temperature, pressure, and $\mathrm{CO}_{2}$ /ethanol proportion ratio on the $\beta$-ecdysone content in the extracts were evaluated. Condition levels for the three independent variables were selected based on the results obtained by Leal et al. (2010). The $\beta$-ecdysone quantification was carried out on a HPLC system by integration of the peak areas at $246 \mathrm{~nm}$ using the external standardization method. The experimental values at various experimental conditions 
Table 2 Main parameters considered for the supercritical fluid extraction (SFE) plant processing Brazilian ginseng roots

\begin{tabular}{|c|c|c|c|c|}
\hline Scenario & & I & II & Unit \\
\hline \multicolumn{5}{|c|}{ Information to set the raw materials inlet flow } \\
\hline Raw material processed & & 29.76 & & $\mathrm{~kg} / \mathrm{h}$ \\
\hline Raw material moisture content & & 0.66 & & $\%$ \\
\hline $\mathrm{CO}_{2} /$ ethanol proportion ratio & & $90: 10$ & & $\%(\mathrm{w} / \mathrm{w})$ \\
\hline Solvent mass to feed mass ratio $(S / F$ & & 50 & & \\
\hline \multicolumn{5}{|l|}{ Information to set the equipment } \\
\hline Raw material cleaning soil removal & (Block CLEANING, Fig. 3) & 60 & & $\%$ \\
\hline Raw material moisture after drying & (Block DRYER, Fig. 3) & 10 & & $\%$ \\
\hline Extraction pressure & (Blocks P-C1 and P-E1, Fig. 3) & 20 & 10 & $\mathrm{MPa}$ \\
\hline Extraction temperature & (Blocks H-C2 and H-E2, Fig. 3) & 303 & 323 & $\mathrm{~K}$ \\
\hline Extraction time & (Block EXTRACTOR, Fig. 3) & 3.5 & 3.5 & $\mathrm{~h}$ \\
\hline Extraction yield & & 0.36 & 0.26 & $\%$ (dry basis) \\
\hline$\beta$-ecdysone content in the extract & & 3.06 & 8.00 & $\%$ \\
\hline Ethanol recovery pressure & (Blocks H-E1 and F-E1, Fig. 3) & 0.016 & & $\mathrm{MPa}$ \\
\hline Ethanol recovery temperature & & 348 & & $\mathrm{~K}$ \\
\hline
\end{tabular}

Table 3 Main parameters considered for the simulation of the sugarcane biorefinery producing first and second generation ethanol

\begin{tabular}{lll}
\hline Parameter & Value & Unit \\
\hline Juice extraction, treatment, and concentration & & \\
Raw material processed & 500 & $\mathrm{t} / \mathrm{h}$ \\
Efficiency of impurities removal on sugarcane & 60 & $\%$ \\
$\quad$ cleaning & & \\
Efficiency of sugars extraction on the milling system & 97 & $\%$ \\
Raw material moisture content & 50 & $\%$ \\
Recovery of sugars on juice treatment & 99.4 & $\%$ \\
Second generation ethanol production from bagasse & & \\
Pretreatment catalyzed steam explosion temperature & 463 & $\mathrm{~K}$ \\
Hemicellulose-xylose conversion & 61.4 & $\%$ \\
Enzymatic hydrolysis temperature & 323 & $\mathrm{~K}$ \\
Reactor solids load & 5 & $\%$ \\
Cellulose-glucose conversion & 69.2 & $\%$ \\
Fermentation & & \\
Fermentation yield & 89 & $\%$ \\
Distillation and dehydration & & \\
Ethanol recovery on distillation and dehydration & 99.7 & $\%$ \\
\hline
\end{tabular}

Data from Ensinas et al. (2013)

are presented in Table 6 . The use of $\mathrm{CO}_{2}$ /ethanol proportion ratio of 90:10\% (w/w) produced extracts with the highest mass of $\beta$-ecdysone per mass of extract of the studied conditions. Statistical analysis to evaluate the influence of the studied parameters on the results was performed for better conclusions. $\mathrm{CO}_{2} /$ ethanol proportion ratio was very statistically significant $(p<0.01 ; p=0.00008)$ for this response variable, while temperature and pressure showed no influence ( $p=0.212719$ and $p=0.378168$, respectively).
Seabra et al. (2010) studying the effect of several $\mathrm{CO}_{2}+$ co-solvents mixtures as extracting solvent has demonstrated that extracting solvent composition is the most significant process parameter, corroborating our findings.

SFE using $\mathrm{CO}_{2}$ and ethanol as co-solvent is regarded as a clean process, and its principle is based on the solvating properties of the supercritical fluid, which can be obtained by employing pressure and temperature above the critical point of the mixture. Besides the tunable nature of supercritical fluids, some other features like the characteristics of the sample matrix and interaction with targeted analysts factors could also be key parameters during this process (Pereira and Meireles 2010). Although a huge number of parameters influence the SFE process, some of them might have no statistical significant effect on it. Proper experimental design and statistical analysis in adjusting the SFE parameters become important tools in this regard and is becoming very popular (Sharif et al. 2014). With the use of a full factorial design $2 \times 2 \times 3$ and ANOVA tools it was observed that for $\beta$ ecdysone selective recovery some well-known tunable SFE process parameters like temperature and pressure in the range studied had an unexpected no statistical effect on this response variable. On the other hand, comparing the $\beta$-ecdysone content in the extracts obtained in this study with those obtained by Leal et al. (2010) using the same $\mathrm{CO}_{2}$ /ethanol proportion ratio and pressure (runs E 1 and E 7) it can be seen that the increase in temperature from $303 \mathrm{~K}$ to those used in this study (323-363 K) enhanced the recovery this bioactive compound.

An increase in extraction temperature during pressurized fluid extraction is reported to improve the efficiency of extraction because of enhanced diffusion rate and solubility of analytes in solvents (Santos et al. 2012b). 
Table 4 Heat flow, initial, and final temperature of streams considered for thermal integration
Legend: Scenario Iexperimental data from Leal et al. (2010); Scenario IIexperimental data from the best condition determined experimentally in the present study

\begin{tabular}{|c|c|c|c|c|c|c|c|}
\hline & \multirow{2}{*}{$\begin{array}{l}\text { Heat } \\
\text { exchanger } \\
\text { (Fig. 3) }\end{array}$} & \multicolumn{3}{|c|}{ Scenario I } & \multicolumn{3}{|c|}{ Scenario II } \\
\hline & & $\begin{array}{l}T_{\text {inicial }} \\
(\mathrm{K})\end{array}$ & $\begin{array}{l}T_{\text {final }} \\
(\mathrm{K})\end{array}$ & $\begin{array}{l}\text { Heat flow } \\
(\mathrm{kJ} / \mathrm{s})\end{array}$ & $\begin{array}{l}T_{\text {inicial }} \\
(\mathrm{K})\end{array}$ & $\begin{array}{l}T_{\text {final }} \\
(\mathrm{K})\end{array}$ & $\begin{array}{l}\text { Heat flow } \\
(\mathrm{kJ} / \mathrm{s})\end{array}$ \\
\hline \multicolumn{8}{|l|}{ Cold streams } \\
\hline Air heating for ginseng drying & H-A1 & 298 & 373 & 13.6 & 298 & 373 & 13.6 \\
\hline $\mathrm{CO}_{2}$ heating prior to extraction & $\mathrm{H}-\mathrm{C} 2$ & 268 & 303 & 10.5 & 268 & 323 & 24.4 \\
\hline $\begin{array}{l}\text { Ethanol heating prior } \\
\text { to extraction }\end{array}$ & H-E2 & 314 & 422 & 5.2 & 314 & 467 & 8.1 \\
\hline Ethanol evaporation & H-E1 & 281 & 348 & 12.7 & 281 & 348 & 12.7 \\
\hline \multicolumn{8}{|l|}{ Hot streams } \\
\hline $\mathrm{CO}_{2}$ cooling prior pumping & $\mathrm{H}-\mathrm{C} 1$ & 298 & 263 & 14.4 & 298 & 263 & 14.4 \\
\hline $\mathrm{CO}_{2}$ cooling prior recirculation & $\mathrm{H}-\mathrm{C} 3$ & 379 & 298 & 33.8 & 379 & 298 & 33.8 \\
\hline $\begin{array}{l}\text { Ethanol cooling prior } \\
\text { recirculation }\end{array}$ & H-E3 & 351 & 298 & 11.8 & 351 & 298 & 11.8 \\
\hline
\end{tabular}

Table 5 Input data used for the economic potential estimation and sensitivity analysis

\begin{tabular}{|c|c|c|c|c|c|}
\hline & Scenario A & Scenario B & Lower & Upper & Price \\
\hline \multicolumn{6}{|l|}{ Raw materials prices } \\
\hline Brazilian ginseng roots & $1.5^{\mathrm{a}}$ & $1.5^{\mathrm{a}}$ & $0.13^{\mathrm{a}}$ & $4.71^{\mathrm{a}}$ & USD/kg \\
\hline Ethanol & $0.72^{\mathrm{b}}$ & $0.49 *$ & & & $\mathrm{USD} / \mathrm{L}$ \\
\hline $\mathrm{CO}_{2}$ & $0.60^{\mathrm{c}}$ & $0.30^{\mathrm{c}}$ & & & USD/kg \\
\hline Electricity & $0.07^{\mathrm{b}}$ & $0.05^{\mathrm{b}}$ & & & USD/kWh \\
\hline \multicolumn{6}{|l|}{ Product and co-product prices } \\
\hline Price for $\beta$-ecdysone in the extracts & $86.29^{\mathrm{d}}$ & $86.29^{\mathrm{d}}$ & & & $\mathrm{USD} / \mathrm{g}$ \\
\hline Leftover Brazilian ginseng roots & - & 1.00 & $0.01^{\mathrm{e}}$ & $16.00^{\mathrm{e}}$ & $\mathrm{USD} / \mathrm{kg}$ \\
\hline \multicolumn{6}{|c|}{ * Ethanol production cost calculated by the simulation } \\
\hline \multicolumn{6}{|l|}{ a Júnior (2005) } \\
\hline \multicolumn{6}{|l|}{ b Albarelli et al. (2013) } \\
\hline \multicolumn{6}{|l|}{ c Santos et al. (2012c) } \\
\hline \multicolumn{6}{|l|}{${ }^{\mathrm{d}}$ Herbarium (2013) } \\
\hline e Crini (2006) & & & & & \\
\hline
\end{tabular}

Considering the statistical results, the use of lower level of pressure $(10 \mathrm{MPa})$ and temperature $(323 \mathrm{~K})$ and $\mathrm{CO}_{2} /$ ethanol proportion ratio (90:10\%,w/w) is the optimum SFE conditions for $\beta$-ecdysone selective recovery ( $7.99 \pm 0.28 \%$ of the extract content is $\beta$-ecdysone). Since in international market, extracts are commercialized at prices that directly depend on bioactive compounds concentration $\beta$-ecdysone content in the extracts was selected as the unique response variable for this study. Indeed, the increase in its concentration from 3.7 (obtained by a previous study) to $8.0 \%$ would reflect in a considerable increase in its selling price. Here, we have to emphasize that the plant used in both studies were cultivated at the same location using the same cultivation methods, minimizing environmental influence on plant bioactive compounds production.

Comparing with other literature data, the results obtained in this study are very promising. The patent
US6224872 (Shibuya et al. 2001) presents an alternative method for obtaining $\beta$-ecdysone-rich extracts from $P$. glomerata. The extraction technique presented involves water heating at $353 \mathrm{~K}$ for the bioactive compounds source. The processing time reaches $24 \mathrm{~h}$, and the final yield of extract is $0.046 \%$ (dry basis), being the $\beta$-ecdysone content in the extract is $1 \%$ (dry basis). Meanwhile, in this study the $\beta$-ecdysone content in the extracts ranged from 2.54 to $8.08 \%$.

Analysis of the production of bioactive compounds by supercritical technology

For the production of $\beta$-ecdysone-rich extract by supercritical technology the simulations were considering the operation of the system under the conditions experimentally studied by Leal et al. (2010) (employing $\mathrm{CO}_{2}+$ ethanol 
Table 6 Summary of the process conditions and experimental results (mean value \pm standard deviation)

\begin{tabular}{lllll}
\hline Run & $\begin{array}{l}\text { Temperature } \\
(\mathrm{K})\end{array}$ & $\begin{array}{l}\text { Pressure } \\
(\mathrm{MPa})\end{array}$ & $\begin{array}{l}\mathrm{CO}_{2} \text { /ethanol } \\
\text { proportion ratio } \\
(\%, \mathrm{w} / \mathrm{w})\end{array}$ & $\begin{array}{l}\beta \text {-ecdysone } \\
\text { content in the } \\
\text { extract }(\%)\end{array}$ \\
\hline E 1 & 323 & 10 & $90: 10$ & $7.99 \pm 0.28$ \\
E 2 & 323 & 10 & $50: 50$ & $6.47 \pm 0.16$ \\
E 3 & 323 & 10 & $0: 100$ & $2.54 \pm 0.08$ \\
E 4 & 323 & 20 & $90: 10$ & $8.08 \pm 0.36$ \\
E 5 & 323 & 20 & $50: 50$ & $7.14 \pm 0.10$ \\
E 6 & 323 & 20 & $0: 100$ & $2.65 \pm 0.06$ \\
E 7 & 363 & 10 & $90: 10$ & $8.04 \pm 0.08$ \\
E 8 & 363 & 10 & $50: 50$ & $7.50 \pm 0.10$ \\
E 9 & 363 & 10 & $0: 100$ & $4.50 \pm 0.19$ \\
E 10 & 363 & 20 & $90: 10$ & $7.89 \pm 0.30$ \\
E 11 & 363 & 20 & $50: 50$ & $6.15 \pm 0.20$ \\
E 12 & 363 & 20 & $0: 100$ & $3.55 \pm 0.15$ \\
\hline
\end{tabular}

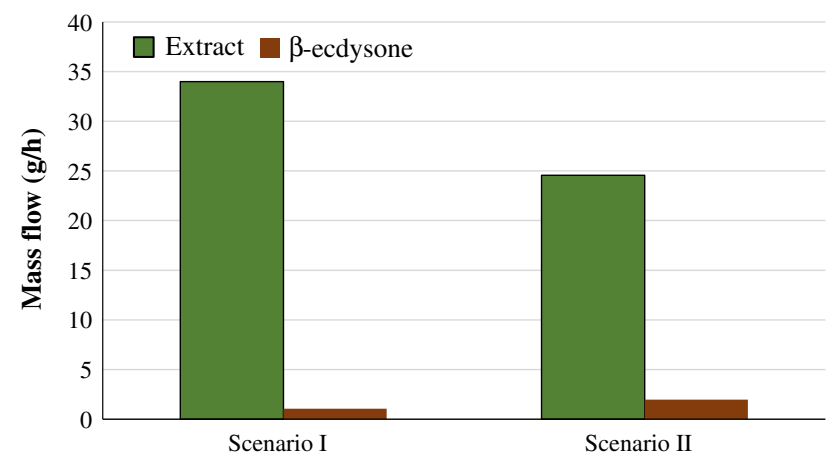

Fig. 4 Extract and $\beta$-ecdysone productivity by supercritical technology considering the SFE process under the conditions experimentally studied by Leal et al. (2010) and under the optimized condition determined experimentally in the present study, Scenarios I, and II, respectively

$(90: 10 \%, w / w)$ at $20 \mathrm{MPa}$ and $303 \mathrm{~K})$ and under the optimized condition determined experimentally in the present study [employing $\mathrm{CO}_{2}+$ ethanol $(90: 10 \%$, w/w) at $10 \mathrm{MPa}$ and $323 \mathrm{~K}$ ], Scenarios I and II, respectively.

Extract and $\beta$-ecdysone production at both scenarios is shown in Fig. 4. Comparing the scenarios, Scenario I presented higher extract production although with lower $\beta$ ecdysone content than Scenario II. On the other hand, it was possible to produce 2.16 times more $\beta$-ecdysone in Scenario II, than in Scenario I.

The SFE process is mainly composed by seven thermal streams, four cold streams that need heating: (i) heating of air for raw material drying, (ii) heat of the solvent $\mathrm{CO}_{2}$ used at the extraction unity, (iii) heat of the solvent ethanol used at the extraction unity, and (iv) ethanol recovery trough evaporation steps and three hot streams that need cooling: (i) $\mathrm{CO}_{2}$ cooling prior pumping, (ii) $\mathrm{CO}_{2}$ cooling for recirculation, and (iii) ethanol cooling for recirculation steps.

Typically, SFE plants are designed as multipurpose plants, where extracts from different raw materials are produced. If the extraction process is considered without energy integration, the thermal energy requirement for Scenario I and II would be 40.3 and $29.9 \mathrm{kWh} / \mathrm{g}$ of $\beta$ ecdysone in the extract, respectively and the cooling demand for the system would be of 57.7 and $30.6 \mathrm{kWh} / \mathrm{g}$ of $\beta$-ecdysone in the extract for Scenarios I and II, respectively.

Considering the thermal integration of these streams through the pinch method, it was possible at both Scenarios (I and II) to supply all heat demand by the cooling of the $\mathrm{CO}_{2}$ for recirculation, when considering one depressurization step after extraction. In a complete isolated continuous extraction process the $\mathrm{CO}_{2}$ recirculation system could be used to supply the heat necessary for the process and cooling utility should be bought from the grid.

It could be an attractive solution for many SFE processes around the world. Although, if the Brazilian scenario is taken into account, the possibility of placing this extraction technology near a very consolidate industrial segment such as the sugarcane sector it could bring even more benefits for the process in terms of energy and economics.

Considering Scenario A, where the SFE plant is located beside a sugarcane biorefinery but as a stand-alone process, using only the cogeneration system to supply heat and electricity for the process. As previously discussed, the heat demand of the system for Scenario IA and IIA is supplied by the cooling of $\mathrm{CO}_{2}$ for its recirculation. The heat produced by the burning of the Brazilian ginseng extraction material leftover is not necessary for the SFE process, therefore, it is used for electricity generation in a condensing turbine. As $\mathrm{CO}_{2}$ needs to be compressed to its recirculation, the electricity consumption is high, but its cooling represents the pinch point of the system, supplying heat to all streams at lower temperatures. The electricity requirement for compressing the $\mathrm{CO}_{2}$ is in the energetic point of view the limiting factors to the process. Considering the burning of the ginseng roots leftover $2.9 \mathrm{kWh} / \mathrm{kg}$ of ginseng leftover is produced, and therefore around $37 \mathrm{~kW}$ of electricity is produced in both Scenario I and II. Considering the depressurization of the extraction equipment in a single phase, with only one flash tank to $0.1 \mathrm{MPa}$, the electricity consumption would be $102 \%$ higher than the electricity produced by the burning of the ginseng roots leftover. In this situation, the $\mathrm{CO}_{2}$ cooling (from 752 to $298 \mathrm{~K}$ ) could also be used for steam generation when integrated with the steam network, which would increase the electricity production in around $45 \%$. Even though, still the net electricity balance would be negative, 
Fig. 5 Grand composite curves for a stand-alone SFE plant under the conditions experimentally studied by Leal et al. (2010) (Scenario IA) without the integration with the steam network

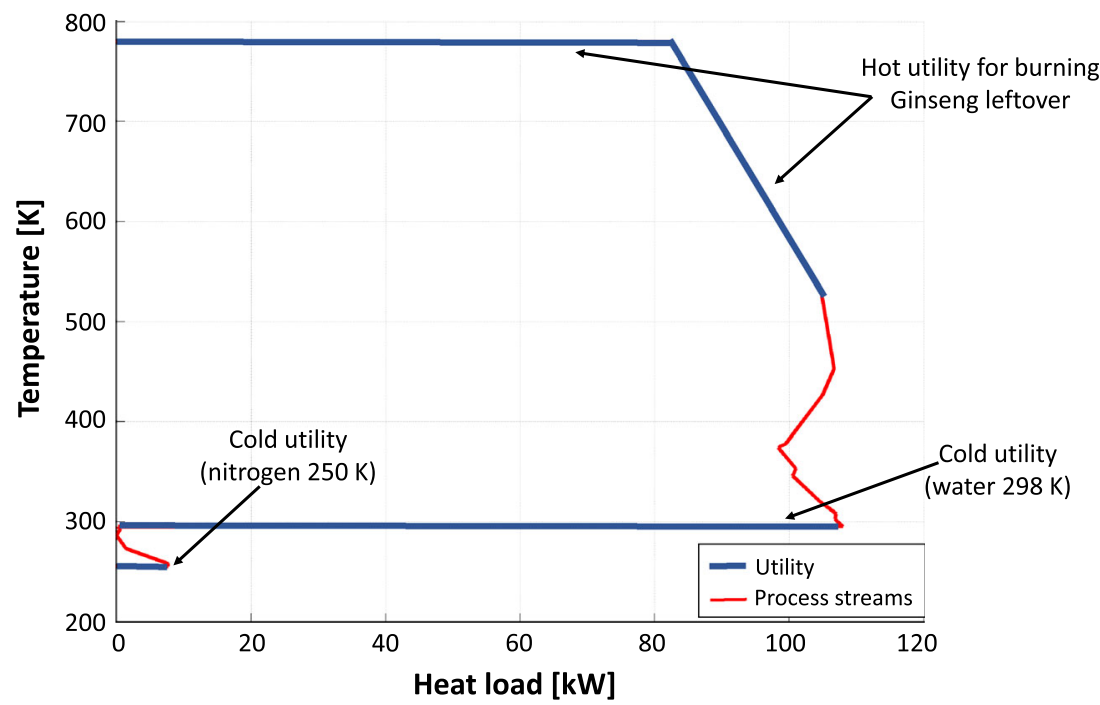

representing that would be necessary to buy $28 \mathrm{~kW}$ of electricity from the grid. In a final effort to decrease electricity consumption two depressurization steps were analyzed, the first at $6.5 \mathrm{MPa}$ and a posterior at $0.1 \mathrm{MPa}$. In this situation, the overall electricity consumption was diminished in $80 \%$ as less $\mathrm{CO}_{2}$ is compressed to recirculation. It was possible to supply both thermal and electricity demand for both scenarios.

Figure 5 shows the grand composite curve without the steam network for Scenario I, it represents the difference between the heat available and the cold streams in relation to the pinch point at a corrected temperature (Linnhoff et al. 1982). Both, Scenario AI and AII presented very similar heat cascade as only the extraction temperature was different. The heat load for burning the ginseng roots leftover is of $105 \mathrm{~kW}, 4 \mathrm{~kW}$ of heat demand, $10.3 \mathrm{~kW}$ of cold utility at $298 \mathrm{~K}$, and $8.1 \mathrm{~kW}$ of cold utility at $250 \mathrm{~K}$ is necessary for the extraction process (not considering the preheating of the air used in the burner) for Scenario AI. For Scenario AII, it is necessary $6.4 \mathrm{~kW}$ of heat demand, $1.7 \mathrm{~kW}$ of cold utility at $298 \mathrm{~K}$ and $6.4 \mathrm{~kW}$ of cold utility at $250 \mathrm{~K}$. Electricity production in Scenario AI and AII was 14.1 and $7.5 \mathrm{kWh} / \mathrm{g}$ of $\beta$-ecdysone in the extract, respectively.

Analysis of a SFE plant integrated to a sugarcane biorefinery

Another configuration that could bring benefits to the SFE process might be its integration to the sugarcane biorefinery producing first and second generation ethanol from sugarcane. It could be an interesting solution to the sugarcane biorefinery to have a multipurpose extraction unit operating in situ as it could be used to add value to its residue as the case of extraction of bioactive compounds from the filter cake created at the juice treatment for ethanol production (Prado et al. 2011). The interaction can also benefit the extraction process, as $\mathrm{CO}_{2}$ and ethanol are available at the sugarcane biorefinery with lower cost. The $\mathrm{CO}_{2}$ produced during fermentation could also be used to enhance the growth of different biomass material that can be used as raw material to the extraction process. Recently it was demonstrated that $\mathrm{CO}_{2}$-enriched atmosphere improves growth of P. glomerata (Saldanha et al. 2013). The integration of the thermal streams of these systems could also be an advantage for the both processes.

Integrating both Scenario I and II to the sugarcane biorefinery, initially, very little thermal benefit could be accounted, since the scale of the extraction process is much smaller than the biorefinery. The thermal streams for the biorefinery present thermal demand (in $\mathrm{kW}$ ) almost 2,000 times higher than in the extraction process, as the biorefinery operates with an inlet flow of raw material $(\mathrm{kg} / \mathrm{h})$ almost 20,000 bigger than the extraction plant.

This difference in the scale could more beneficial if more energy was required to the extraction process, as if a pressurized liquid extraction (PLE) is considered. Figure 6 shows the contribution of the SFE process to the sugarcane biorefinery composite curve (Scenario IIB). The composite curve for the extraction process expressed in red compared to the sugarcane biorefinery, expressed in blue, is drawn as a line due the difference in scale. If a bigger scale extraction process was considered, the composite curve of the process would be shown similar to Fig. 5, and the possibility for integration with the sugarcane biorefinery could be better evaluated. This could be the case when considering the use of sugarcane waste, as the filter cake, for extraction. 
Fig. 6 Integrated composite curve of the supercritical fluid extraction (SFE) process under the conditions experimentally studied by Leal et al. (2010) with the sugarcane biorefinery producing first and second generation ethanol (blue line) (Scenario IB). (Color figure online)

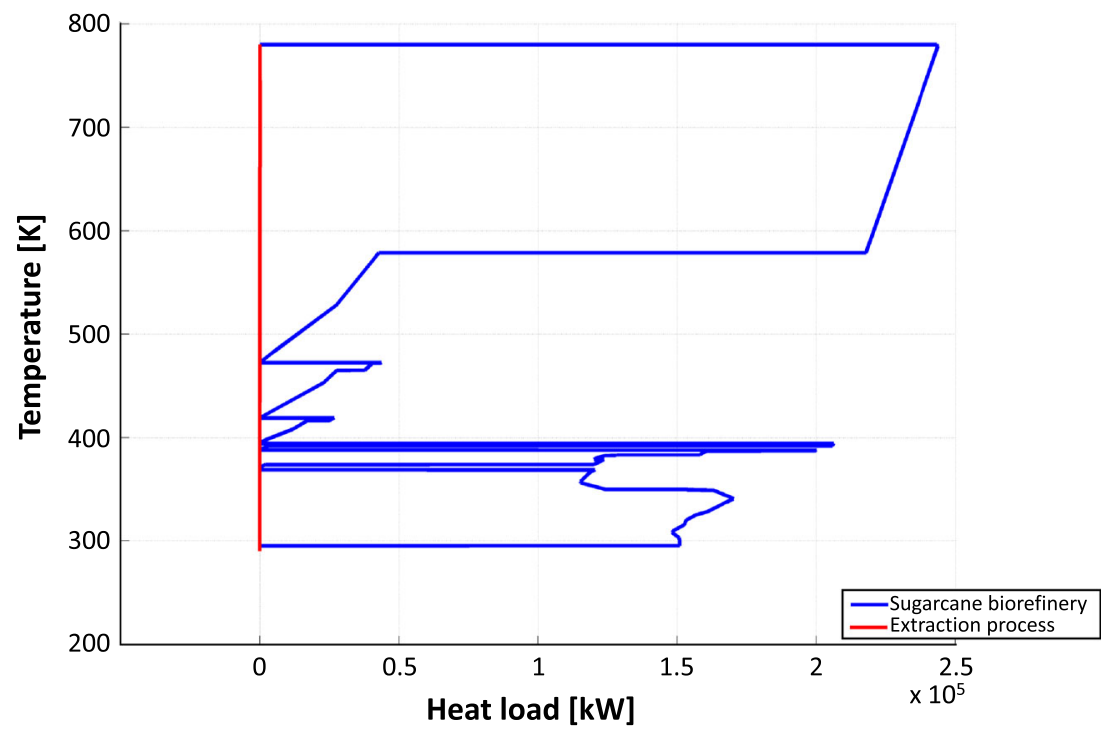

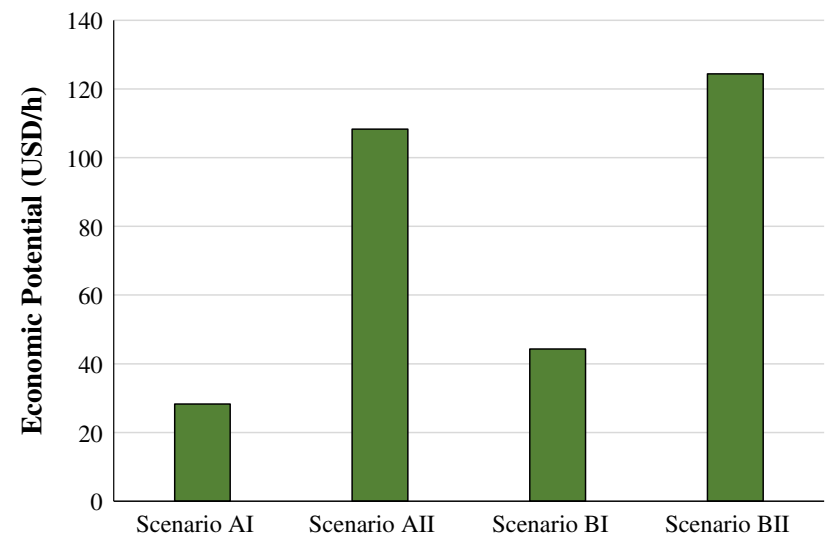

Fig. 7 Economic potential of the four scenarios evaluated Iextraction system based on experimental data from Leal et al. (2010); II-extraction system based on experimental data from the present study; A-stand-alone SFE plant with shared cogeneration with a sugarcane biorefinery; B-SFE plant integrated with a sugarcane biorefinery

Economic benefits

It was analyzed the EP of the four scenarios evaluated (Fig. 7), the EP was calculated for the scenarios considered thermal integration either in a stand-alone SFE process (Scenarios IA and IIA) or in a SFE process integrated with the biorefinery (Scenarios IB and IIB). The EP of the processes can give a good initial estimative of the influence of the studied parameters at the economic feasibility of the process as it takes into account the expenditure and benefit each process analyzed. As both Scenarios I and II present very similar process and it is important to take into account that this would be a multipurpose process, the investment for both scenarios will be very similar, therefore only the EP was evaluated to access the scenarios economically.
Scenario II presented 3.8 times higher EP than Scenario I when not integrated with the sugarcane biorefinery (Scenario A) and 2.8 times when integrated (Scenario B). The integration with the biorefinery increased in 57 and $15 \%$ the EP for Scenarios I and II, respectively. Scenario IIB is from the energetic and economic point of view the most attractive alternative for $\beta$-ecdysone-rich extract production from $P$. glomerata roots.

Some of the assumed costs for raw material and price for the products can vary depending on different assumptions for the market. Therefore, a sensitivity analysis was performed varying the CRM (Fig. 8) and the price for possibly selling the leftover extracted material (Fig. 9).

The cost for the raw material can vary depending of different factors as cultivation and environmental conditions, pretreatment before selling the roots, and others. Assuming that measures could be taken to enhance this raw material productivity, as using $\mathrm{CO}_{2}$ at the cultivation stage, the cost of this material would decrease, increasing the EP of the scenarios. From the sensitivity analysis (Fig. 8), it was found that the cost of $2.42 \mathrm{USD} / \mathrm{kg}$ is the maximum cost when the EP is positive for all scenarios. For the costs of 3.57 and $4.71 \mathrm{USD} / \mathrm{kg}$, representing a raw material possibly already prepared and/or a small cultivation due to seasonal problems, the Scenarios A studied are not feasible as the EP is negative.

The ginseng roots leftover after extraction could be sold to different uses, as animal feed, as fuel to cogeneration together with other waste biomass, as a natural biosorbent (Albarelli et al. 2011) and other uses. Therefore, its price can vary depending on the use and its logistics. For Scenario A, it was not considered the selling of this leftover as it was necessary to produce electricity to supply the electricity demand of the SFE process, so it 


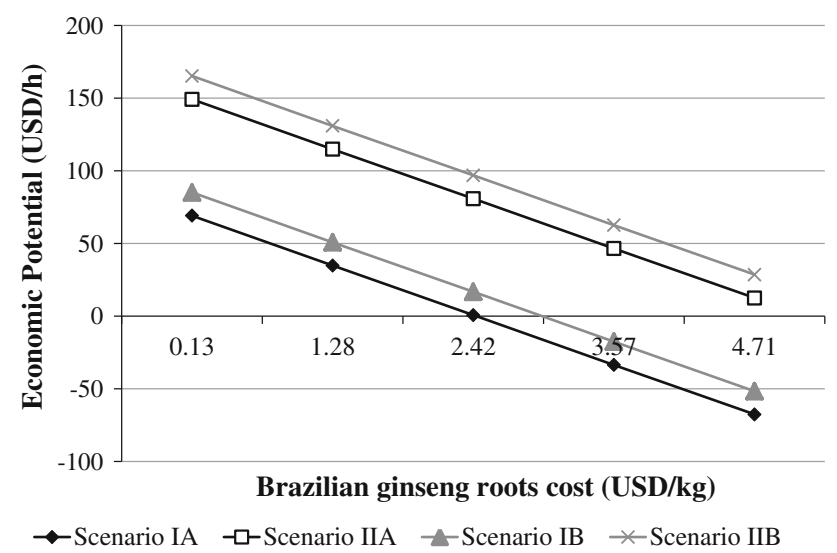

Fig. 8 Sensitivity analysis varying the cost of the raw material for the four scenarios evaluated: I-extraction system based on experimental data from Leal et al. (2010); II-extraction system based on experimental data from the present study; A-stand-alone SFE plant with shared cogeneration with a sugarcane biorefinery; B-SFE plant integrated with a sugarcane biorefinery

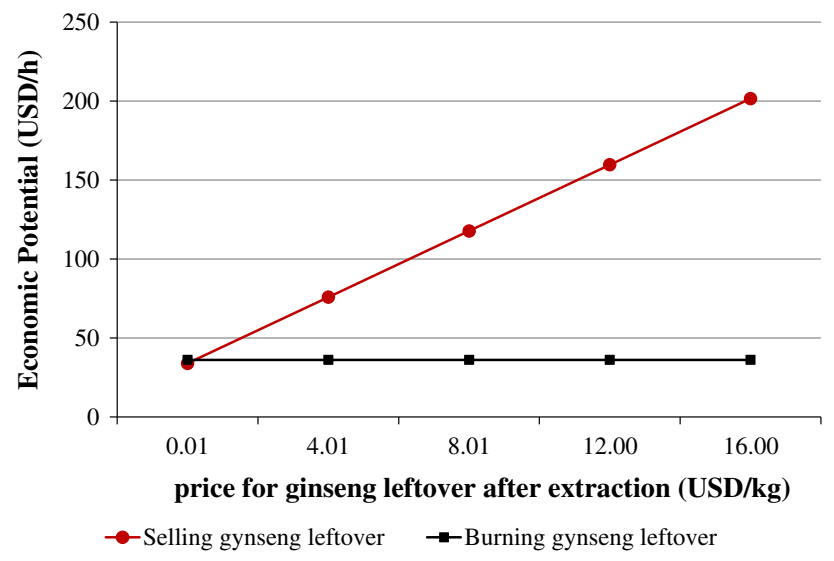

Fig. 9 Sensitivity analysis varying the price for possibly selling the ginseng leftover after extraction for the extraction system based on experimental data from Leal et al. (2010) integrated with a sugarcane biorefinery (Scenario IB)

was used as fuel for the cogeneration system. In Scenario $\mathrm{B}$, as the thermal demand is supplied by the integration with the sugarcane biorefinery and electricity at lower cost can be bought from the biorefinery instead of the grid, it was analyzed the selling of the leftover material. In this extend, Fig. 9 shows Scenario IB considering the burning of the ginseng roots leftover to energy production and the selling of this material at different prices. For the lowest value studied $0.01 \mathrm{USD} / \mathrm{kg}$, the gain for the selling the leftover is really small, increasing less than $1 \%$ the EP of Scenario IB. According to Ernesto et al. (2009), the value for selling sugarcane bagasse is around of 0.004-0.014 USD/kg in dry base, similar to the lowest value assumed for the sensitivity analysis $(0.01 \mathrm{USD} / \mathrm{kg}$ of ginseng roots leftover, Table 5). This low value, probably corresponding to the selling of this leftover to be used as fuel or animal feed, would not be interesting for the SFE process as $6.5 \%$ higher EP could be achieved considering the burning of this material.

Preview studies (Albarelli et al. 2011) showed that biomass materials could be used as adsorbent, after bioactive compounds recovery, to remove heavy metal ions. Considering a high added-value application, as the use of the leftover material as biosorbent, which the selling price can achieve values as high as $10-15$ USD $/ \mathrm{kg}$, depending on its adsorption capacity (Crini 2006), the EP for the process would be much higher than considering the leftover burning. When a price of $16 \mathrm{USD} / \mathrm{kg}$ is considered, the increase in the economic potential, comparing with the burning of the leftover material, is of $82 \%$. Very similar behavior is found for Scenario IIB, where at the lowest price for the ginseng roots leftover, the burning of the material represents an EP $19 \%$ higher than the selling of the material, and at the highest price the selling of the material represents an increase of $59 \%$ on the EP compared with the burning.

Experiments are under evaluation for the determination of the adsorption capacity of leftover extracted P. glomerata roots, aiming the increase of the economical potential of our proposed integrated biorefinery. Preliminary results demonstrated that the adsorption properties of $P$. glomerata roots in natura were compared with those of banana peels, a well-known low cost natural adsorbent (Santos et al. 2012d).

\section{Conclusion}

SFE process evaluated experimentally at the present study showed higher selective extraction for $\beta$-ecdysone from Brazilian ginseng ( $P$. glomerata) roots, providing an extract with 2.16 times higher $\beta$-ecdysone than the results obtained in previous studies. Thermal integration of the SFE process diminished energy requirements of the process, resulting in a reduction of cold utility requirement of 69 and $87 \%$ and a final electricity demand of 14.1 and $7.5 \mathrm{kWh} / \mathrm{g}$ of $\beta$-ecdysone in the extract, considering the SFE process under extraction conditions defined by literature and by optimized condition determined experimentally in the present study.

The construction of a SFE plant inside or in close proximity to a sugarcane biorefinery demonstrated to be very promising, increasing the EP of the SFE process in $15 \%$ under the optimized condition determined experimentally, since the SFE plant could use directly the ethanol, $\mathrm{CO}_{2}$, heat, and electricity already available, avoiding logistics costs. Another interesting point of this new proposal, which can be extended for other bioactive 
compounds sources besides Brazilian ginseng roots, is the possibility of the use of the cogeneration system of the sugarcane biorefinery to burn the leftover extracted material. In this case, the process waste material would be used to produce electricity and/or thermal energy that would be consumed by the process, contributing to the biomass integral valorization. The thermal benefit accounted for the thermal integration of the SFE plant to the sugarcane biorefinery producing first and second generation ethanol was not expressive as the thermal integration of the extraction process itself already diminishes the heat demand in $90 \%$ for both cases. The integration of the extraction process to the biorefinery was more expressive economically for the scenario that studied the SFE process under extraction conditions defined by literature, increase of $57 \%$ of the EP comparing with the not integrated process. Even though, the best economic results were found for the optimized condition determined experimentally in the present study integrated to the biorefinery, EP of 124.4 USD/h. In a situation in which the Brazilian ginseng roots price was increased to 4.71 USD/g, only the SFE integrated with the biorefinery solution would be economically feasible. Finally, the selling of the ginseng roots leftover could be an interesting answer to increase the economical attractiveness of the integrated SFE process to the biorefinery. However, this option would only present a better EP than using this material as a cogeneration fuel when the selling price is higher than $0.2 \mathrm{USD} / \mathrm{g}$.

Acknowledgments Diego T. Santos and Maurício A. Rostagno would like to thank the FAPESP (Processes 10/16485-5, 12/19304-7, 13/15049-5) for the fellowships. Juliana Albarelli would like to thank CNPq for the postdoctoral fellowship (Process 245662/2012-0). The authors acknowledge the financial support from CNPq and FAPESP (Processes 09/17234-9; 12/10685-8).

\section{References}

Albarelli JQ, Rabelo RB, Santos DT, Beppu MM, Meireles MAA (2011) Effects of supercritical carbon dioxide on waste banana peels for heavy metal removal. J Supercrit Fluids 58:343-351. doi:10.1016/j.supflu.2011.07.014

Albarelli JQ, Ensinas AV, Silva MA (2013) Product diversification to enhance economic viability of second generation ethanol production in Brazil: The case of the sugar and ethanol joint production. Chem Eng Res Des. doi: 10.1016/j.cherd.2013.11. 016

Arai K, Smith RL Jr, Aida TM (2009) Decentralized chemical processes with supercritical fluid technology for sustainable society. J Supercrit Fluids 47:628-636. doi:10.1016/j.supflu.2008.11.008

Bollinger R (2010) Méthodologie de la synthèse des systèmes énergétiques Industriels. PhD Thesis, École Politechnique Fédérale de Lausanne, Switzerland

Crini G (2006) Non-conventional low-cost adsorbents for dye removal: a review. Bioresour Technol 97:1061-1085. doi:10. 1016/j.biortech.2005.05.001
Ensinas AV, Codina V, Marechal F, Albarelli J, Silva MA (2013) Thermo-economic optimization of integrated first and second generation sugarcane ethanol plant. Chem Eng Trans 35:523-528. doi:10.3303/CET1335087

Ernesto VART, Ribeiro CA, Hojo O, Fertonani FL, Crespi MS (2009) Thermal characterization of lignocellulosic residue from different sugarcane. J Therm Anal Calorim 97:653-656. doi:10.1007/ s10973-009-0370-3

GLPK (2014) GNU Linear Programming Kit. http://www.gnu.org/ software/glpk/. Accessed 04 Feb 2014

Herbarium (2013) Ginseng Brasil Herbarium 45 Comprimidos. PanVel Farmácias. http://www.panvel.com/panvel/visualizarPro duto.do?codigoItem $=385395$. Accessed 08 Nov 2013

Júnior IM (2005) Avaliação de genótipos de Pfaffia glomerata (Spreng.) pedersen visando seu cultivo comercial. Dissertation, University of Campinas

King JW, Srinivas K (2009) Multiple unit processing using sub- and supercritical fluids. J Supercrit Fluids 47:598-610. doi:10.1016/j. supflu.2008.08.010

Leal PF, Kfouri MB, Alexandre FC, Fagundes FHR, Prado JM, Toyama MH, Meireles MAA (2010) Brazilian ginseng extraction via LPSE and SFE: global yields, extraction kinetics, chemical composition and antioxidant activity. J Supercrit Fluids 54:38-45. doi:10.1016/j.supflu.2010.03.007

Linnhoff B, Towsend DW, Boland D, Hewitt GF, Thomas BEA, Guy AR, Marsland RH (1982) A user guide on process integration for the efficient use of energy. The Institution of Chemical Engineers, Rugby

Marechal F, Kalitventze B (1998) Process integration: selection of the optimal utility system. Comput Chem Eng 22:S149-S156. doi:10. 1016/S0098-1354(98)00049-0

Meireles MAA (2008) Extraction of bioactive compounds from Latin American plants. In: Martinez J (ed) Supercritical fluid extraction of nutraceuticals and bioactive compounds. CRC, Boca Raton

Pasquel A, Meireles MAA, Marques MOM, Petenate AJ (2000) Extraction of stevia glycosides with $\mathrm{CO}_{2}+$ water, $\mathrm{CO}_{2}+$ ethanol, and $\mathrm{CO}_{2}+$ water + ethanol. Braz J Chem Eng 17:271-282. doi:10.1590/S0104-66322000000300003

Pereira CG, Meireles MAA (2010) Supercritical fluid extraction of bioactive compounds: fundamentals, applications and economic perspectives. Food Bioprocess Technol 3:340-372. doi:10.1007/ s11947-009-0263-2

Prado JM, Prado GHC, Meireles MAA (2011) Scale-up study of supercritical fluid extraction process for clove and sugarcane residue. J Supercrit Fluids 56:231-237. doi:10.1016/j.supflu. 2010.10.036

Rostagno MA, Debien ICN, Vardanega R, Nogueira GC, Barbero GF, Meireles MAA (2014) Fast analysis of $\beta$-ecdysone in Brazilian ginseng (Pfaffia glomerata) extracts by high-performance liquid chromatography using a fused-core column. Anal Methods 6:2452-2459. doi:10.1039/C3AY42276C

Saldanha CW, Otoni CG, Notini MM, Kuki KN, Cruz ACF, Neto AR, Dias LLC, Otoni WC (2013) A $\mathrm{CO}_{2}$-enriched atmosphere improves in vitro growth of Brazilian ginseng [Pfaffia glomerata (Spreng.) Pedersen]. In Vitro Cell Dev Biol Plant 49:433-444. doi:10.1007/s11627-013-9529-5

Santos DT, Veggi PC, Meireles MAA (2012a) Optimization and economic evaluation of pressurized liquid extraction of phenolic compounds from jabuticaba skins. J Food Eng 108:444-452. doi:10.1016/j.jfoodeng.2011.08.022

Santos DT, Albarelli JQ, Meireles MAA (2012b) Simulation of an integrated sustainable production of extract from Brazilian ginseng roots with a cogeneration plant. Chem Eng Trans 29:91-96. doi:10.3303/CET1229016 
Santos DFL, Rebelato MG, Rodrigues AM (2012c) Analysis of the economic viability of a plant to capture $\mathrm{CO}_{2}$ in the alcohol industry. Rev Gest Tecnol 12:64-88

Santos DT, Albarelli JQ, Rabelo RB, Beppu MM, Meireles MAA (2012d) Characterization of Brazilian ginseng roots and its adsorption properties for heavy metal removal Effects of supercritical carbon dioxide on waste banana peels for heavy metal removal. In: Proceedings of XIX Brazilian Congress of Chemical Engineering, Buzios, RJ, Brazil

Seabra IJ, Braga MEM, Batista MT, Sousa HC (2010) Effect of solvent $\left(\mathrm{CO}_{2} /\right.$ ethanol/ $\left.\mathrm{H}_{2} \mathrm{O}\right)$ on the fractionated enhanced solvent extraction of anthocyanins from elderberry pomace. J Supercrit Fluids 54:145-152. doi:10.1016/j.supflu.2010.05.001

Sharif KM, Rahman MM, Azmir J, Mohamed A, Jahurul MHA, Sahena F, Zaidul MHA (2014) ISM experimental design of supercritical fluid extraction-a review. J Food Eng 124: 105-116. doi:10.1016/j.jfoodeng.2013.10.003
Shibuya T, Ario T, Fukuda S (2001) Composition. Patent US6224872 STATISTICA (2001) Statistica, Users Manual release 7

Straccia MC, Siano F, Coppola R, La Cara F, Volpe MG (2012) Extraction and characterization of vegetable oils from cherry seed by different extraction processes. Chem Eng Trans 27:391-396. doi:10.3303/CET1227066

Tang MC, Chin MWS, Lim KM, Mun YS, Ng RTL, Tay DHS, Ng DKS (2013) Systematic approach for conceptual design of an integrated biorefinery with uncertainties. Clean Technol Environ Policy 15:783-799. doi:10.1007/s10098-013-0582-x

Turton RB, Wallace B, Whiting JS, Bhattacharyya D (2003) Analysis, synthesis and design of chemical processes. Prentice Hall, Upper Saddle River

Zimmer AR, Bruxel F, Bassani VL, Gosmann G (2006) HPLC method for the determination of ecdysterone in extractive solution from Pfaffia glomerata. J Pharm Biomed Anal 40:450-453. doi:10.1016/j.jpba.2005.07.016 